\title{
Verification of the Wind Response of a Stack Structure
}

\author{
D. Makovička, J. Král, D. Makovička \\ This paper deals with verification analysis of the wind response of a power plant stack structure. Over a period two weeks the actual history of \\ the dynamic response of the structure, and the direction and intensity of the actual wind load was measured, reported and processed with the \\ use of a computer. The resulting data was used to verify the design stage data of the structure, with the natural frequencies and modes \\ assumed by the design and with the dominant effect of other sources on the site. In conclusion the standard requirements are compared with \\ the actual results of measurements and their expansion to the design load.
}

Keywords: stack structure, wind load, dynamic response, experimental verification.

\section{Introduction}

The stack structure of a desulphurization absorber (Fig. 1), consisting of a steel skeletal tower structure adjoining the absorber vessel, terminates in a GRP (glas fiber reinforced plastics) extension. The purpose of the analysis is to assess the response of the steel tower structure and its GRP extension with reference to the design loads. The work is based on a theoretical as well as an experimental analysis of the structure. The experimental verification of the dynamic response was based on the measurements of the vibrations of both the steel parts and the GRP parts of the structure excited by the effects of wind and other sources generated by the machines in the power plant area, and by a test pulse generated by a hammer impact on the wall of the GRP extension. The vibration measurements proceeded repeatedly in an extended form (an increased number of monitored points) with reference to instantaneous excitation values and on a long-term basis on selected sites for about 14 days, with 15-minute repetition to determine the long term development of the response to wind effects. The measured vibration histories in terms of acceleration, velocities and relative deformations, together with the measurements of wind velocity and direction, were evaluated by a computer and compared with the response values assumed in the design, with the natural frequencies of the GRP extension according to the designer's computation and with the frequencies of the dominant vibration sources - major machines in the environs of the stack.

\section{Description of the structure}

The principal part of the structure (Fig. 1) is a vertical GRP stack structure mounted above the absorber vessel. The stack is supported and partly surrounded by a supporting steel lattice structure on which the horizontal flue is also suspended at the point of its inlet into the absorber vessel. The steel structure is anchored in four pile footings.

The GRP stack tube between the levels of +29.680 and +120.220 was assembled from 14 segments of $7000 \mathrm{~mm}$ inside diameter and $6610 \mathrm{~mm}$ assembly length. The wall thickness varies between $2.0+9.0 \mathrm{~mm}$ and $2.0+23.6 \mathrm{~mm}$, where the $2.0 \mathrm{~mm}$ layer forms a chemical barrier protecting the structure against the weather. The GRP tube is constrained at +30.935 in the vertical and horizontal directions by a steel structure. Horizontal displacements are also prevented at three further levels $(+51.190,+71.647$ and +92.116 ), where the tube is strutted horizontally against the steel structure by means of buffers on the circumference of the tube enabling, however, vertical displacements.

The supporting steel structure between +0.600 and +92.300 was erected as a lattice tower comprising mostly tubular sections. It consists of four columns mutually con-

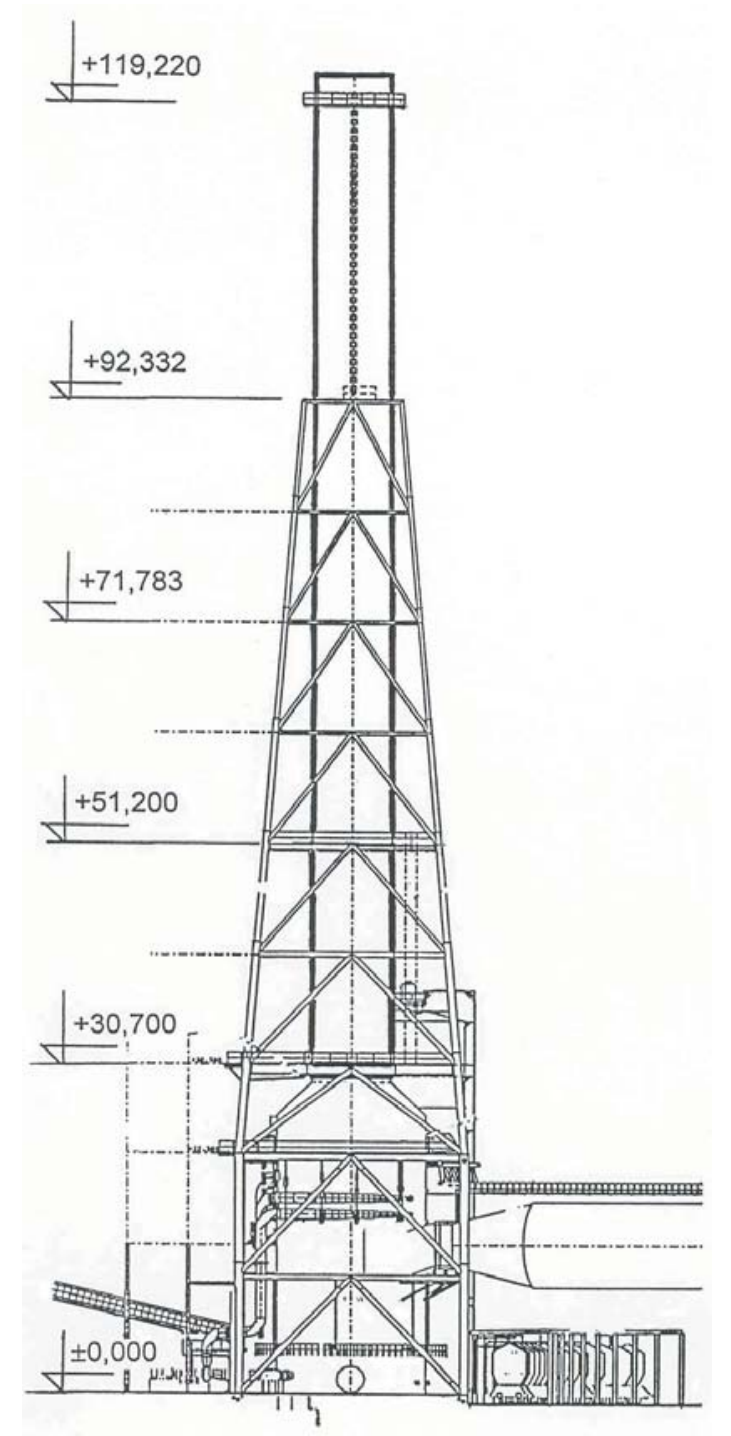

Fig. 1: Schematic drawing of the stack structure 


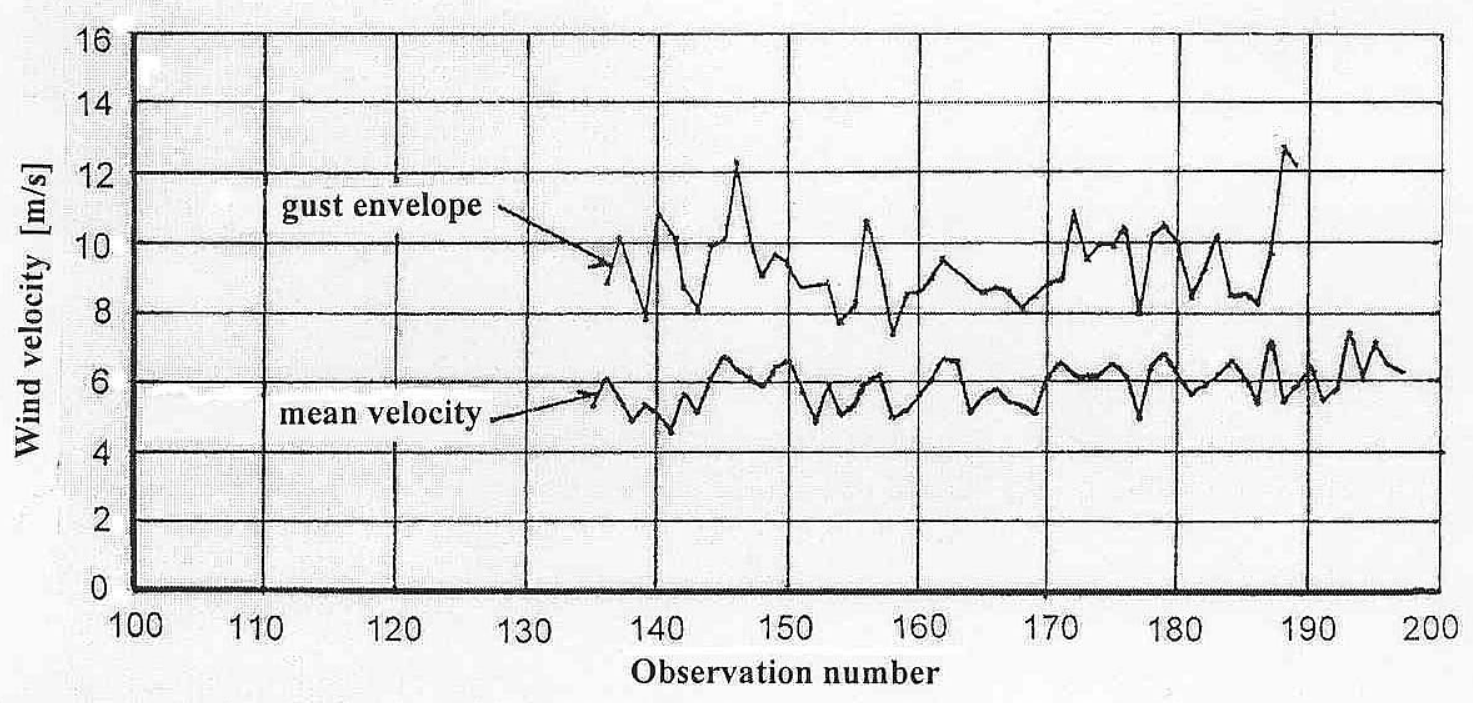

Fig. 2: Comparison of 10-minute mean wind velocities with maximum gusts of wind during measurements

a)

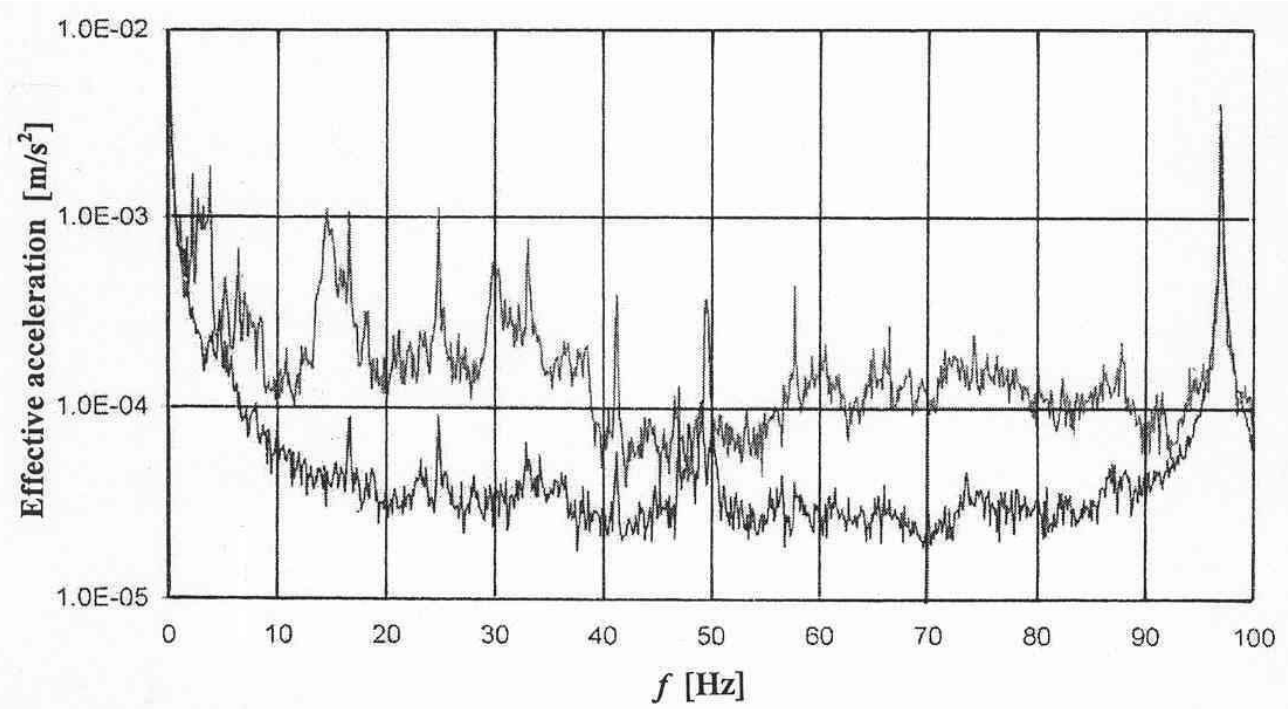

b)

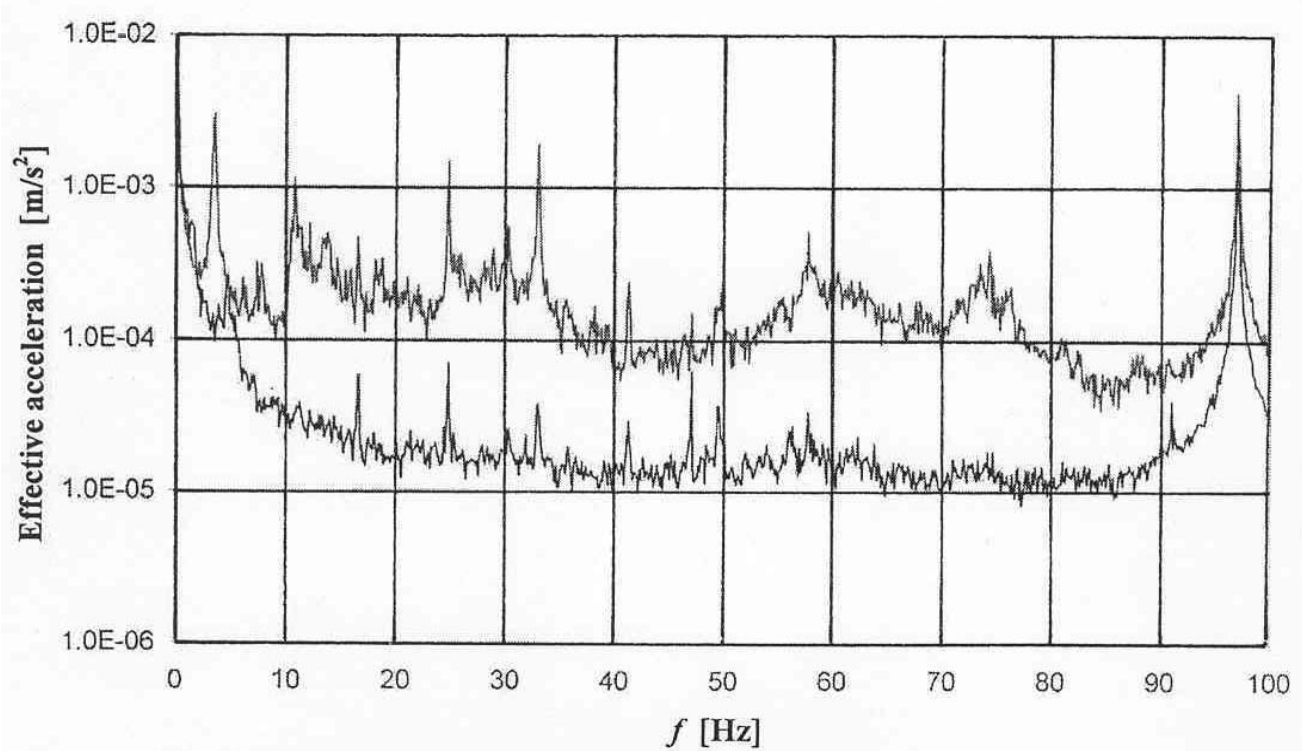

Fig. 3: Autospectra of acceleration, transmission of vibrations from the footings to the steel tower structure at +31 level: a) horizontally in the East-West direction, b) vertically 
nected by horizontal beams on nine levels and stiffened by diagonal diaphragms. Below the +22.500 level the steel tower plan is of $20.0 \times 20.0 \mathrm{~m}$ dimensions, while above this level its dimensions decrease linearly to the top of the tower at the +92.300 level, where the dimensions are $8.6 \times 8.6 \mathrm{~m}$. Until the +30.700 level the steel tower passes through the steel skeleton of the hall housing the absorber technology. The steel part of the structure is founded on four concrete footings at the +0.600 level. Every footing is mounted on a bored pile $1220 \mathrm{~mm}$ diameter and $8300 \mathrm{~mm}$ length. At their feet the piles are constrained in sound granite bedrock. To prevent the piles from being pulled out of the bedrock (to intercept the tensile forces) the pile heads are anchored by prestressed anchors.

\section{Load}

With reference to the limit states of its safety the dominant load applied to the tower structure is the wind load. The measurements of wind velocity and direction were made on the level of the platform approximately at +53 level. The measuring set projected horizontally approx. $2 \mathrm{~m}$ from the tower structure to ensure that the measured values were minimally influenced by the bypassing air flow. The objective was to record the response to various instantaneous wind velocities (Fig. 2) and directions.

Another load applied was the test force pulse. To define the magnitude of the test pulse load applied to the structure a test hammer was used. The test hammer was provided with a force sensor in its punch, enabling measurements of the pulse force at the moment of its application to the surface of the GRP structure across a rubber pad. The response of the structure to the hammer pulse was measured within the $0-1000 \mathrm{~Hz}$ frequency band. The purpose of these measurements was to make an accurate determination of the spectrum of the natural frequencies of the structure. The test hammer was situated on the western side of the tower at approximately $+48 \mathrm{~m}$ level. Finally the response measurements used were also to determine of other sources excited by the power plant machinery in the proximity of the stack structure.

\section{Description of Response Measurements and Evaluation}

The sites for response monitoring were selected both on the footings on the pile heads and on the steel tower structure and its GRP extension, in order to provide the data necessary for determining of the phase shift between the movements of the two parts of the structure (steel and GRP). The selection of the measuring sites was also adjusted to ensure accessibility from the galleries, fixed ladders and their landings, so that we could monitor the three-dimensional movement of the structure with reference to load magnitude and character. The stack response consisted, consequently, of the response to technical seismicity (effect of machines in the power-plant area, which was practically of a stationary character, and the response to wind effects, which were mostly of a non-stationary character (gusty wind). When the test pulses were applied during low wind velocities, their effects were superposed on the machinery and wind effects. The history of the response records to the above loads was described by the basic statistical characteristics (mean and effective value, maximum and minimum). As it was impossible to measure the state without a load, the records were described by the effective value and the maximum double amplitude (maximum - minimum). The integration of the filtered acceleration records yielded velocity records and dynamic displacements, also described in the above mentioned manner.

The response records were analysed with reference to frequency; their autospectra (Fig. 3) show both the frequencies of the forced vibrations due to technical seismicity and the natural frequencies of the structure. Further the coherence functions between the response records on various sites and the corresponding transfer functions were evaluated from which the vibration modes of the structure during the lowest natural frequencies were derived (Fig. 5).

For the purpose of extrapolation of the measured response to the design loads the measured wind velocities for the individual records were converted to the basic wind pressure

$$
w=v^{2} / 1600,
$$

where $v$ is wind velocity $[\mathrm{m} / \mathrm{s}]$, $w$ is wind pressure $\left[\mathrm{kN} / \mathrm{m}^{2}\right]$.

The wind velocity and direction measurements were made on a selected site parallel with the response measurements on the other sites. In simplified terms, it was assumed that the distribution of the measured wind pressure in all other points (both vertically and around the horizontal circumference of the GRP extension and steel tower structure) corresponds with standard requirements. With regard to stack height and the height of the buildings on its windward side it was assumed that the wind velocity variation with height corresponded with ground category II (Eurocode, open landscape). The velocity at a height of some $53 \mathrm{~m}$ above ground level is about 1.32 times as high as that at the height of $10 \mathrm{~m}$ above ground level. The wind direction during the measurements was easterly to northeasterly. The mean wind velocity can be considered, in simplified terms, as the average wind velocity in 10-minute intervals. The maximum measured ten-minute mean wind velocities attained 6-7 m/s (Fig. 2). The differences between the average value of the whole interval and the instantaneous (peak) velocity can be considered as the effect of a gust of wind. The coefficient of wind gusts in the design load was considered as $G=1.8$. The measured values are obvious from the comparison of the curves in Fig. 2. The reference wind velocity (10-minute mean wind velocity $10 \mathrm{~m}$ above ground level with annual occurrence probability 0.02 for region 2) was considered with the design value of $v_{\text {ref, } 0}=26.7 \mathrm{~m} / \mathrm{s}$.

This velocity is higher than required by the national application document of the respective Eurocode (CSN P ENV 1991-2-4) $v_{\text {ref, } 0}=26 \mathrm{~m} / \mathrm{s}$. The measured velocities of $6-7 \mathrm{~m} / \mathrm{s}$ correspond with the mean wind velocity $10 \mathrm{~m}$ above ground level (category II) (6 to 7) / $1.32=4.5$ to $6.3 \mathrm{~m} / \mathrm{s}$. The response of the structure under the design load, consequently, can be estimated from the measured response values by means of the ratio of the squares of the reference velocity and the measured wind velocity $10 \mathrm{~m}$ above ground level, i.e. 
${\text { (design reference velocity })^{2}}^{2}$

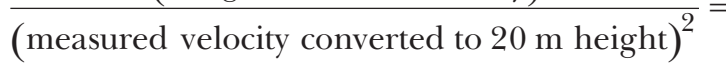

$$
=\frac{26.7^{2}}{(4.5 \text { to } 5.3)^{2}}=
$$

$=35$ to 25 times the measured response values.

The design load used in the structural design or the response computed from it express as the equivalent effect of the mean time-variable random load component. Direct measurement of this response required measurement of the state without a load, i.e., the response at a wind velocity of
$0 \mathrm{~m} / \mathrm{s}$ and the response to a defined stationary load. There was no state without a load during the measurements. For this reason it was necessary to base the measurements on the instantaneous wind velocity at which the response of the structure was measured in terms of acceleration within the frequency band of $0-100 \mathrm{~Hz}$. The double integration of the centered acceleration from selected records yielded the history of the displacement excited by the effects of wind and technical seismicity. The displacement record had a significant quasistatic component corresponding with the changing instantaneous wind velocity fluctuating about the mean wind velocity.

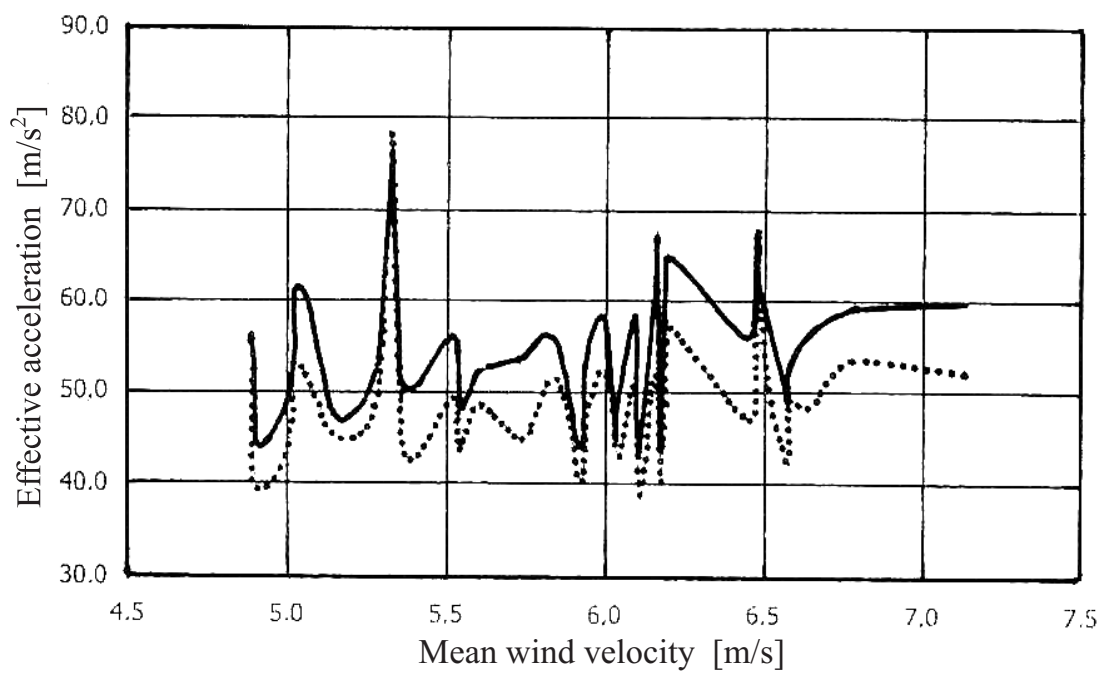

Fig. 4: Effective acceleration at the top of the GRP extension $(+121)$ plotted against wind velocity in the wind direction - lengthwise (solid line) and transversal (dotted line)

Table 1: Measured accelerations $\left[\mathrm{mm} / \mathrm{s}^{2}\right]$ in the $0-40 \mathrm{~Hz}$ frequency interval, in two perpendicular horizontal directions (the first sensor in approximately East/West wind direction, the other in the transverse direction)

\begin{tabular}{|c|c|c|c|c|c|c|}
\hline \multirow{4}{*}{ Value } & \multicolumn{6}{|c|}{ Position of pickups in relation to structure height and wind direction } \\
\hline & \multirow{2}{*}{\multicolumn{2}{|c|}{$\begin{array}{c}\text { GRP extension } \\
+121\end{array}$}} & \multicolumn{4}{|c|}{ Steel tower } \\
\hline & & & \multicolumn{2}{|c|}{+91} & \multicolumn{2}{|c|}{+51} \\
\hline & Lengthwise & Transversal & Lengthwise & Transversal & Lengthwise & Transversal \\
\hline \multicolumn{7}{|c|}{ Acceleration $\left[\mathrm{mm} / \mathrm{s}^{2}\right] \ldots$ Effective value of dynamic response component } \\
\hline Mean value & 55.0 & 49.4 & 16.9 & 11.1 & 7.4 & 8.0 \\
\hline Maximum & 76.9 & 78.3 & 21.5 & 22.6 & 10.5 & 12.4 \\
\hline Minimum & 43.2 & 38.2 & 12.7 & 7.0 & 5.3 & 5.7 \\
\hline \multicolumn{7}{|c|}{ Acceleration $\left[\mathrm{mm} / \mathrm{s}^{2}\right] \ldots$ Measured maximal effective value (quasistatic + dynamic components) } \\
\hline Mean value & 254.1 & 217.8 & 73.1 & 48.4 & 33.4 & 38.2 \\
\hline Maximum & 398.0 & 367.5 & 93.8 & 84.4 & 46.1 & 60.6 \\
\hline Minimum & 175.0 & 168.6 & 53.0 & 31.0 & 22.5 & 23.9 \\
\hline \multicolumn{7}{|c|}{ Acceleration $\left[\mathrm{mm} / \mathrm{s}^{2}\right] \ldots$ Measured minimal effective value (quasistatic + dynamic components) } \\
\hline Mean value & -256.1 & -222.9 & -72.3 & -47.9 & -34.8 & -37.8 \\
\hline Maximum & -185.6 & -167.1 & -52.6 & -29.0 & -20.4 & -26.3 \\
\hline Minimum & -328.4 & -404.9 & -93.9 & -76.8 & -55.3 & -65.8 \\
\hline
\end{tabular}


Table 2: Vibration displacements [mm] in the $0-40 \mathrm{~Hz}$ frequency band, for both horizontal directions, extended to displacements corresponding to the design wind velocity and dominant flexural frequency $1.06 \mathrm{~Hz}$.

\begin{tabular}{|c|c|c|c|c|c|c|}
\hline \multirow{4}{*}{ Value } & \multicolumn{6}{|c|}{ Position of pickups in relation to structure height and wind direction } \\
\hline & \multirow{2}{*}{\multicolumn{2}{|c|}{$\begin{array}{c}\text { GRP extension } \\
+121\end{array}$}} & \multicolumn{4}{|c|}{ Steel tower } \\
\hline & & & \multicolumn{2}{|c|}{+91} & \multicolumn{2}{|l|}{+121} \\
\hline & Lengthwise & Transversal & Lengthwise & Transversal & Lengthwise & Transversal \\
\hline \multicolumn{7}{|c|}{ Displacement $[\mathrm{mm}]$... Effective value of dynamic response component } \\
\hline Mean value & 50.1 & 45.0 & 15.4 & 10.1 & 6.8 & 7.3 \\
\hline Maximum & 47.6 & 48.5 & 13.3 & 14.0 & 6.5 & 7.7 \\
\hline Minimum & 56.8 & 50.3 & 16.7 & 9.2 & 6.9 & 7.5 \\
\hline \multicolumn{7}{|c|}{ Displacement $[\mathrm{mm}]$... Measured effective value of total displacement (quasistatic + dynamic components) } \\
\hline Mean value & 239.1 & 206.1 & 67.7 & 44.8 & 31.9 & 35.5 \\
\hline Maximum & 399.2 & 427.8 & 101.5 & 89.3 & 52.2 & 64.9 \\
\hline Minimum & 148.7 & 128.0 & 48.4 & 26.0 & 19.1 & 21.9 \\
\hline
\end{tabular}

The dynamic component of the displacement of the structure was superimposed on the quasistatic component. The long-time records contained record sections in which the wind velocity as well as the quasistatic component of the displacement of the structure dropped to a minimum approaching the non-loaded state. In such a case the difference between the maximum and the minimum displacements could be considered as the overall response corresponding to the mean wind velocity of the given record. The probable magnitude of the response of the structure to wind effects under the design load could then be estimated by multiplying the ascertained response by the ratio of the squares of the design and measured wind velocities in accordance with the above considerations.

\section{Natural frequencies}

The measured response histories (due to wind effects and pulse excitation by means of the test hammer) were used to compute the response frequency spectra, which revealed that the lowest measured frequencies corresponded with the natural vibration frequencies of the structure. The records taken on the +121 level show the dominant frequency peaks (Fig. 4) on the level of approx. $1.06 \mathrm{~Hz}, 2.13-2.19 \mathrm{~Hz}$ (the stack stiffness is not identical in both horizontal directions due to the service ladders - a fact expressed by the interval of measured frequencies); $2.63-2.94 \mathrm{~Hz}, 3.69-3.82 \mathrm{~Hz}$, $4.75 \mathrm{~Hz}, 5.56 \mathrm{~Hz}, 6.19 \mathrm{~Hz}$. Annexed Fig. 5 shows the lowest vibration modes for the East-West direction. The evaluated natural vibration frequencies correspond to the computed natural vibration modes. The lowest basic flexural vibration mode of the structure of $1.06 \mathrm{~Hz}$ can be observed in all vibration records also on the lower vertical levels of the structure. The frequency of $3.4 \mathrm{~Hz}$ obviously corresponds with the vertical natural vibration mode as compared with the computed natural vertical vibration frequency of $2.8 \mathrm{~Hz}$. The frequency shift of the measured natural frequency as compared with the computed natural frequency enables us to conclude that the erected structure is somewhat stiffer than considered by the design.

\section{Frequency spectra due to effects from other sources}

The frequency spectra computed from the measured response histories show further dominant frequency peaks (apart from the natural mode frequencies) - see Fig. 3 and Fig. 4. These dominant peaks correspond with the effects of other sources - e.g., technical seismicity propagating into the structure from its environs through the foundation soil. As a rule, the dominant seismic effects are generated by the operation of major machines or mechanisms in the power plant area. Let us compare the dominant higher frequency peaks with revolution frequencies and higher harmonic frequencies of the machines in the near environs in the given area. The basic revolution frequency of the turbogenerator sets is $50 \mathrm{~Hz}$ and their higher harmonic frequencies are $100 \mathrm{~Hz}, 150 \mathrm{~Hz}$, etc. incl. the half-harmonic frequency of $25 \mathrm{~Hz}$. The basic revolution frequency of the cooling tower pumps is $8.18 \mathrm{~Hz}$, that of the compressors is $94.3 \mathrm{~Hz}$ in one station and $153.3 \mathrm{~Hz}$ in the other station, and that of the drives of both compressors is $25 \mathrm{~Hz}$. It is known that under higher loads the compressor revolutions fluctuate about their rated values and, consequently, the measured values differ or may differ in the order of $1 \mathrm{~Hz}$. A comparison of the measured frequencies of the records with the revolution frequencies of the machines in the technical seismicity sources shows that the stack excitation by technical seismicity is significantly influenced particularly by the cooling tower pumps on a level of $8.2 \mathrm{~Hz}$ and its multiples and the compressors with frequencies in the proximity of $100 \mathrm{~Hz}, 150 \mathrm{~Hz}$ and their multiples. The influence of the turbo-generator sets, due to their higher-quality balancing and obviously better maintenance, participates in the wet stack response at a lower rate than the cooling tower pumps and compressors. 
a)

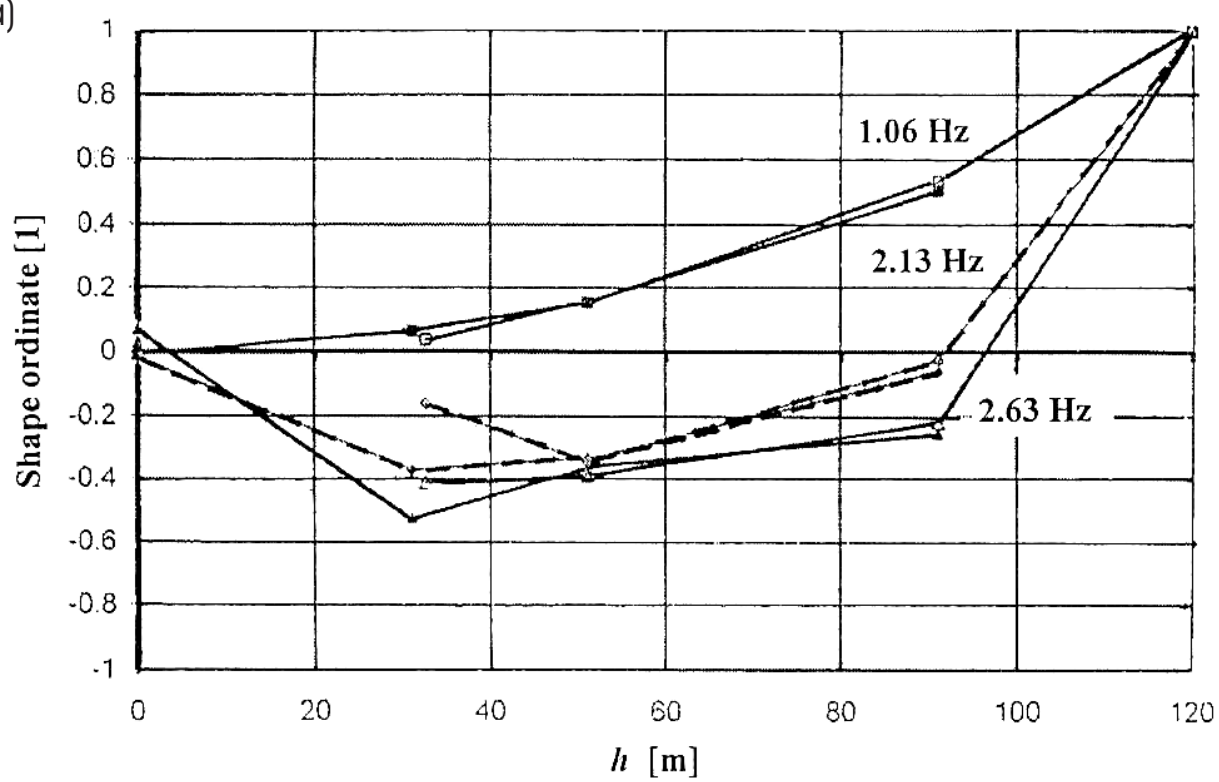

b)

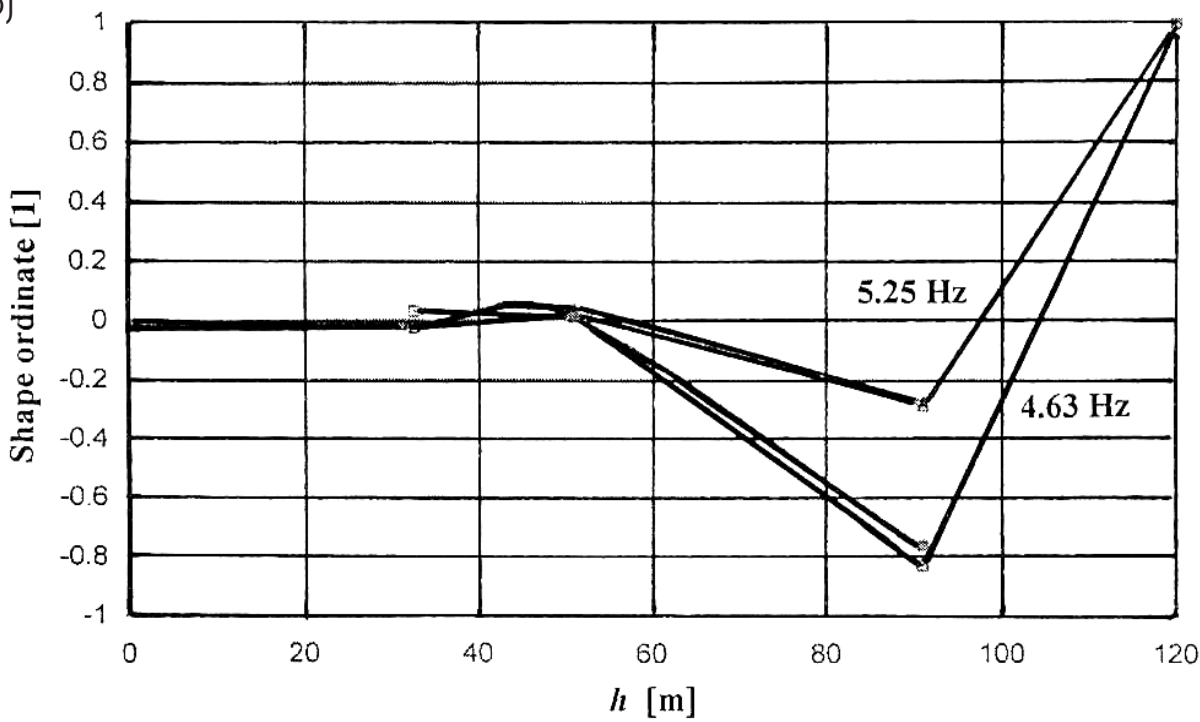

Fig. 5: Normalized measured natural horizontal vibration modes in the wind direction a) first three lowest modes, b) fourth and fifth higher modes

The evaluation monitored particularly the increase in the signal generated by technical seismicity on the level of approx. +31 of the steel structure with reference to the vibrations of the footings of the tower columns (Fig. 3). This increase may be 20 to 30 fold, depending on the frequency of the dominant peak. The comparison shows that the effects of technical seismicity are comparable with wind effects for current wind velocities of about $5-7 \mathrm{~m} / \mathrm{s}$. If we were to compare the seismic effects with the design wind effects, we would find the effect of the technical seismicity lower than the effect of the design wind load. Wind effects usually generate large amplitudes of the structure in the displacements at low frequencies, while technical seismicity generates lower to small displacements, but at higher and very high frequencies, which may be critical for some structural details (such as the joints of structural members, a wide range of measuring probes in the structure, chimney stack warning lights, etc.)

\section{Transmission of effects between steel structure and footings}

Fig. 3a compares the of acceleration spectra in approx. The East-West horizontal direction, i.e., in the wind direction for the sites at +31 and the footings. It is obvious that the steel structure magnifies the effects at the frequencies propagating into the structure through the foundation soil from ambient vibration sources, such as technical seismicity. A significant increase will manifest itself at low frequencies from approx. $1 \mathrm{~Hz}$ to $8 \mathrm{~Hz}$, i.e., in the region of the natural frequencies of the steel structure. At higher frequencies the steel structure has higher damping, yet the transmission of exterior dynamic effects (due to technical seismicity) is significant in the environs of frequencies of $16.5 \mathrm{~Hz}, 25 \mathrm{~Hz}, 33 \mathrm{~Hz}, 45-50 \mathrm{~Hz}$ and $96 \mathrm{~Hz}$. 
Fig. 3b compares the acceleration spectra in the vertical direction for the two above mentioned sites. During vertical vibrations, the transmission from the footings to the structure is dominant, both at the low frequencies in the environs of $1-3 \mathrm{~Hz}$ and at frequencies of $16.5 \mathrm{~Hz}, 25 \mathrm{~Hz}, 33 \mathrm{~Hz}, 42 \mathrm{~Hz}$, $47-50 \mathrm{~Hz}, 58 \mathrm{~Hz}, 74 \mathrm{~Hz}$ and $96 \mathrm{~Hz}$. These frequency components with significant response peaks on the footing sites are mostly due to technical seismicity analogous with horizontal vibrations.

\section{Conclusions}

Using the example of a composite structure, this paper analyses the influence of wind and technical seismicity effects on the dynamic response and compares the significance of these two load types for the safety and reliability of the structure. The comparison has revealed that the dominant effect on the structure with reference to its safety (maximum displacements, extreme stress state in selected cross sections, etc.) is exercised by the design wind load. The effects of technical seismicity and other sources from the power plant area are comparable with the dynamic wind load within the interval of usual wind velocities. However, technical seismicity may become dominant for the reliability of the structure in the case of vibrations of selected parts, such as joints, measuring probes installed in the structure for technological purposes, etc. Finally, we have qualified these effects, which are sometimes underestimated in the design stage.

The measurements of the response of the structure during "stronger" wind (5-7 m/s) have revealed the obvious advantage of extrapolating of this relatively strong wind to the design load. A comparison of the measured response with its assumed design value makes it possible to determine the reserves of the structure in its actual behaviour and the influence of a wide range of imperfections arising from the co-operation of the structure as a whole: piles - steel tower GRP extension.

\section{Acknowledgement}

This research was supported by Fortum Engineering, Ltd., Pardubice, and formed part of GAČR research pro- ject No. 103/03/0082 "Nonlinear Response of Structures Under Extraordinary Loads and Man Induced Actions" and GAČR project No. 103/03/1395 "Reliability of Local Pressure Measurements on Models in a Boundary Layer Wind Tunnel", for which the authors would like to thank the company and the agencies.

\section{References}

[1] ČSN P ENV 1991 - 1: Basis of Design and Actions on Structure. Part 1: Basis of Design (in Czech), Czech Standard Institute, Prague, 1996.

[2] ČSN P ENV $1991-2$ - 4: Basis of Design and Actions on Structure. Part 2-4: Actions on Structures - Wind Actions .(In Czech), Czech Standard Institute, Prague, 1997.

[3] Model Code for Steel Chimneys, Cicind, Switzerland, 1988.

[4] Commentaries for the Model Code for Steel Chimneys, Cicind, Switzerland, 1989.

[5] Tichý, M. et al: Load of Building Structures. (In Czech), TP 45, Prague: SNTL, 1987.

Doc. Ing. Daniel Makovička, DrSc.

phone: +420224353856

fax: +420224353511

e-mail:makovic@klok.cvut.cz

Ing. Jaromír Král, CSc.

phone: +420224353544

e-mail:jkral@klok.cvut.cz

Klokner Institute

Czech Technical University in Prague

Šolínova 7

16608 Prague 6, Czech Republic

Ing. Daniel Makovička

Static and Dynamic Consulting

Šultysova 167

28401 Kutná Hora

Czech Republic 